\title{
UNCOVERING THE QUALITY OF STEM SERVICE-LEARNING COURSE IMPLEMENTATION AND ESSENTIAL ELEMENTS ACROSS THE CALIFORNIA STATE UNIVERSITY SYSTEM
}

Judy Botelho, Rebecca M. Eddy, Nicole Galport, and Cathy Avila- Linn

\section{Abstract}

With 23 campuses serving nearly 500,000 students, the California State University (CSU) is the largest and most diverse university system in the country. Annually, 3,500 service-learning (SL) courses are offered to more than 67,000 students, $17 \%$ of whom are science, technology, engineering, and mathematics (STEM) majors. However, there is little data on the landscape of these courses and the extent to which they are implemented with fidelity and quality across campuses. This article will summarize the first system-wide, multiyear research study assessing SL in STEM courses and address key gaps in the literature. Specifically, the article will explore how SL is implemented in STEM disciplines across a sample of CSU institutions, common underlying elements in course implementation, and the overall quality of those SL elements within courses. In addressing these questions, this article will also discuss the development of study instruments and the resulting codification of essential SL elements.

\section{Literature Review}

Nearly a quarter of the way into the 21st century, science, technology, engineering, and mathematics (STEM) fields are a hallmark of creativity, progress, and hope. What new technology is on the horizon? What unimaginable idea will this generation of scientists bring to life? These questions are of national concern to the United States as it grapples with its ability to contribute to, and innovate in, STEM industries within the global market. The Pew Research Center reports strong growth in STEM occupations, as "employment ... has grown 79\% since 1990, from 9.7 million to 17.3 million, outpacing overall U.S. job growth" (Graf et al., 2018, para. 1). As a result, it has become increasingly imperative that the United States produce college graduates that are well prepared to meet the needs of the workforce and contribute to advancements in STEM fields. To attain this goal, 
some policy-makers have targeted reducing STEM attrition in college, arguing that retaining more students in STEM fields in college is a low-cost, fast way to produce the STEM professionals that the nation needs (President's Council of Advisors on Science and Technology, 2012).

Nationally, fewer than half of all students who begin postsecondary education complete a degree within 6 years of their first enrollment. The American Institutes for Research reports, "Women, racial/ethnic minorities, and persons with disabilities are underrepresented in the STEM disciplines. Collectively, these demographic groups represent the largest untapped STEM talent pool in the United States” (2012, p. 1). Of the traditionally underrepresented students of color in STEM, only 24\% of African American, Hispanic, and Native American students complete a STEM bachelor's degree within 6 years, compared with $40 \%$ of White students (Hurtado et al., 2008). In 2018, only $21.9 \%$ of engineering degrees were conferred to women, and $19.3 \%$ were awarded to traditionally underrepresented students of color (Roy, 2019).

The California State University (CSU) has had a strong focus on STEM-engaged efforts since 2010, including system-wide efforts to (a) advance STEM student success through the implementation of high-impact practices, (b) institutionalize service learning (SL) in STEM disciplines, and (c) promote college student retention and achievement in STEM disciplines. Through institutes, symposia, infrastructure development, curriculum, and program development, the university system increased its SL course offerings in STEM by 66\% in 4 years. While this increase was promising, the university system wanted to better understand the landscape of these courses and the extent to which they were implemented with fidelity and quality across campuses as a means to promote student success, which led to this system-wide research study.

\section{Utilizing Service-Learning to Advance STEM Education}

Today, the link between STEM education and preparing well-rounded students is growing. As the field evolves, innovators encourage a whole-person approach to learning, "combining physical, mental, social-emotional, and cognitive development with traditional academics” (Milgrom-Elcott, 2019, para. 11). Kuh (2008) highlighted a set of 10 teaching and learning modalities, called "Educationally Purposeful Activities," that have been researched through data from the National Survey of Student Engagement and found to have a significant impact on student success. One of these modalities, SL, has the potential to positively affect the academic achievement, career development, and civic engagement of diverse students.

The theory of student involvement (Astin, 1984/1999) maintains that the quality and quantity of the student's academic and personal development is a direct function of the student's degree of involvement in the academic experience. SL is an interactive pedagogy in that students learn the course material so that they can apply it in a "real-world" setting. Students engage with one another throughout the course through reflection sessions or working in teams. SL courses often require more interaction with faculty or teaching assistants due to the reflective component of the course. The sense of accountability described by Astin et al. (2000) may mean that the student spends more time learning the course material. A 2013 study by Jameson et al. found that SL benefited students' ability to apply knowledge as well as their critical thinking and higher order thinking skills. Addition- 
ally, Lockeman and Pelco (2013) found a significant positive relationship between SL class participation and a higher likelihood of graduating. In terms of major retention, a study of 369 students across five departments and 4 years in school found that $64 \%$ of students reported that SL had a positive impact on the likelihood they would continue in engineering. Females and underrepresented groups indicated a significantly higher positive impact on the likelihood that they would continue in engineering (Barrington \& Duffy, 2007).

While little research exists on whether SL influences students' future employment, earnings, and promotion, a study at the University of Georgia found that graduates with SL experiences had significantly higher starting salaries and significantly shorter time to receiving their first full-time job as well as their first raise than their non-SL counterparts (Matthews et al., 2015). Additionally, a 2005 study found that a student's major or field of study accounts for 25\%-30\% of difference in employment earnings after graduation (Pascarella \& Terenzini, 2005). This supports the Pew Research Center's January 2018 report on the STEM workforce, which indicates that STEM workers earn 26\% more than their non-STEM counterparts.

Research also shows that STEM education is currently falling short in helping to develop students' understanding of social issues. In a 2015 national, longitudinal study comparing undergraduate STEM college students to their non-STEM counterparts on the value they place on helping to create a more equitable world, Garibay found that STEM students viewed working for social change as less important to their career goals. Garibay argues that "STEM education should help develop students' understanding of social issues, their transformative position to rectify structural inequities, and other outcomes important for a more democratic society" (p. 610). STEM SL has the potential to combat this negative trend. In fact, the National Academy of Engineering (2010) encourages educators to integrate humanitarian and social issues into engineering curriculum as they have found that this actively develops engineering students' awareness and understanding of social issues.

\section{Gaps in the Research Literature}

While there is robust evidence of the overall impact of SL on student success, the research is broad and does not delve into the degrees of quality of the SL experiences and the potential of differentiated impacts on specific populations of students, such as first-generation students, students of color, and, in the case of STEM disciplines, females as underrepresented. Billig (2000) states that one of the chief reasons for the lack of deep research on the quality of SL is the variance in its definition, referred to interchangeably as an experience, program, pedagogy, and philosophy (Jacoby \& Associates, 1996). The present study aims to address this gap in the literature by documenting rigorous evidence on the key components of STEM SL and how to assess the implementation quality of those components. Furthermore, this study is exploratory in nature in that it attempts to document the state of STEM SL courses in the CSU system and develop an instrument to determine the essential elements of SL present in these courses. This systematic assessment of SL components and quality of implementation aims to guide the ways in which we prepare faculty and support students in SL and inform curriculum standards, statewide policy, and formulas for funding and facilities allocation.

Given the lack of empirical data in the research literature specifically related to STEM SL courses, we investi- 
gated the following research questions: How is SL in STEM currently being implemented given the vast range of interpretations of SL? What are the common underlying elements in SL implementation? To what degree are the essential elements of high-quality SL present in participating courses in the university system? Other questions, methods, and analyses related to the effects of STEM SL courses on student outcomes are not included in the present article. Additionally, given the multiple definitions of terminology in SL, the terms SL placement and SL project are used interchangeably in this article to describe SL activities. We did not examine whether the essential elements of SL in STEM were different in comparison to other disciplines; we also did not exclude SL experiences in STEM courses based on the type of SL experience (e.g., placement based or project based). Our intention was to explore the variation of SL STEM course experiences across the university system.

\section{Method}

\section{Sampling Procedures}

The original research design planned to implement the study across 132 courses (25\% of the 529 STEM SL courses in the CSU system as of 2012-2013) at a minimum of 13 campuses across the CSU system to obtain a large enough sample for robust data analysis. During Year 1, the research team discovered that the number of STEM SL courses was an overestimation. Additional review of these courses by faculty or the campus SL office indicated that several courses listed were not, in fact, SL. Therefore, a smaller than expected number of faculty members and their students participated in the study, resulting in the reduction of the estimated courses from 132 to 80 .

\section{Faculty Sampling Procedures}

A member of the research team solicited participation in the study using various methods of recruitment, including direct email to deans of STEM departments and through SL offices. Several attempts were made to contact faculty members directly via email and phone calls. Interested faculty members were required to complete an online orientation and memorandum of understanding. After participating faculty and their corresponding STEM SL courses were identified, sampling of students occurred.

\section{Student Sampling Procedures}

The research team initially recruited and communicated with students via a third-party email client during the first phase of the study after participating STEM SL courses and faculty members were identified. Subsequent attempts to recruit study participants were conducted within the first few weeks of the course. Faculty or SL staffers visited participating courses to show a 3-minute video. Students were then given 15 minutes during class 
to complete the pretest survey. The short video included an overview of the study, an explanation of the benefits and incentives for students, survey instructions, and a link to the student survey. Overall, 61\% of students contacted participated in the study by completing at least one study measure.

\section{Participants}

\section{Faculty Participants}

Study participants included 47 STEM faculty from 10 CSU campuses who taught SL courses in one or more terms from fall 2014 to fall 2016. Fourteen of the 47 (35\%) faculty members reported that the course included in the present study was the first time they had taught an SL course. Some faculty members, however, taught multiple sections of the same course during the same term. In this situation, faculty and student data across courses were combined, or clustered together, because the courses were identical. For the purpose of data tracking and analysis, each individual course taught by a specific faculty member, regardless of the course section, was assigned a cluster identification number. As a result, the research study included 32 clusters of courses during Year 1, 34 during Year 2, and 12 in Year 3, for a total of 78 clusters. Courses represented a wide array of STEM disciplines (e.g., chemistry, computer science, environmental studies), specifically 33 clusters in science, 24 in technology, 17 in engineering, and four in mathematics.

\section{Student Participants}

In total, 1,700 unique students participated in the research study. Students of participating STEM SL faculty were eligible to participate. Thirty-six percent of student participants were Hispanic, 53\% were male, and 49\% were Pell-grant eligible (an indication of high need or low socioeconomic status). Only a small portion (20\%) reported that they had previously completed an SL course.

\section{Measures}

\section{Faculty Measures}

Four measures were administered to participating faculty.

1. Faculty pretest survey. Participating faculty members completed a pretest survey at the start of the course to answer questions related to their own background information (discipline) as well as expectations regarding the course. Example questions included: "Is the SL component of the course optional or required for students?" and "Please indicate the level of importance with the following statements (i.e., engaging students, effective pedagogy, etc.) regarding your SL course project.” 
2. Faculty pedagogy survey. Faculty members completed a pedagogy survey at the completion of the course, including questions modified from the Faculty Engagement Survey (Western Region Campus Compact Consortium, 2009), that addressed the essential elements of SL. Example questions included: "Please describe any active learning strategies that you used in the course (e.g., case studies, group projects, integration of social media)" and "In reflecting upon your recent SL course experience, please indicate the extent to which you agree with the following statements (i.e., my awareness of the community has expanded, my relationships with the students have improved)."

3. Faculty course logs. Course logs were administered to faculty members to capture descriptions of classroom activities at the completion of the course. Questions, presented in the form of a rubric, included items the research team developed to align with the 15 Essential Elements of Quality Service-Learning and other SL rubrics (e.g., Dary et al., 2012; National Service-Learning Cooperative, 1999; Peace Corps, 1998), the Faculty Engagement Survey (WRCCC, 2009), and items from previous research (e.g., Hatcher et al., 2004). The descriptions of the classroom activities were coded and scored using a rubric. Information from the log and faculty survey was used to categorize the quality of the STEM SL course and adherence to well-established principles of SL in the literature. Example questions included: "To what extent was the course designed to address community need?" and "How was SL integrated into the curriculum?”

4. Faculty course syllabus. Each faculty member was required to submit a copy of their syllabus for each SL course they taught. These syllabuses were coded by an SL content expert according to the Fundamentals of Service-Learning Course Construction (Heffernan, 2001).

\section{Student Measures}

A total of three measures were administered to students in the larger research study; however, only one is relevant to the current paper and described below. The two additional measures asked students to address their attitudes and behaviors relating to civic engagement and their attitudes about careers within STEM fields at pretest and posttest, which will be discussed in a future paper.

Student Posttest Survey. Students completed a survey at the completion of their SL courses addressing the perceived impact of the course. This instrument was used in conjunction with the faculty course log to create a service-learning quality rubric used to classify participating SL courses. 


\section{Procedures}

\section{Scale Development: Essential Elements of Service-Learning}

Development of essential elements of SL occurred in multiple stages. Initial survey items on the student and faculty SL surveys were developed based on a review of the current literature regarding SL and SL courses (i.e., rubrics and scales identified in faculty course logs above). A total of 24 questions were developed to include on both the faculty course logs and the student posttest survey. Data were collected from both surveys related to the range of SL elements found in the literature. An exploratory approach was taken to create composite variables based on the range of possible areas to generate main categories of essential elements in an SL course. The goal was to statistically combine items into a smaller number of scales that would compose the overall quality of the SL experience. The research team initially sought to determine which of the 15 survey items were most strongly related to one another. As a next step, two raters from the research team reviewed the same survey items, as well as the current literature, to determine which survey items should theoretically be related to one another. This allowed the team to statistically test whether these item groupings did, in fact, represent distinct components of quality.

\section{Service-Learning Course Quality}

The research study aimed to better understand how SL in STEM disciplines was being implemented across multiple institutions within the same system, if there were common underlying elements in implementation, and the overall quality of these elements. The quality of these elements was addressed through the analysis of (a) course syllabuses and (b) student and faculty ratings on the SL posttest questionnaire.

Service-Learning Course Quality Measure 1: Syllabus Coding. Each syllabus was coded on the nine key dimensions identified by Heffernan (2001) on a scale of 0 to 4, with 0 indicating that the dimension was absent from the syllabus and 4 indicating that the dimension was "Exceptional" in the syllabus. A full list of these syllabus dimensions can be found in Table 1. Each syllabus was then given an average score, which represents the overall quality of the syllabus as it relates to SL. These scores were then assigned one of the following quality ratings: very low, low, medium, and high. Table 1 also shows alignment of the syllabus dimensions with essential SL elements developed using survey data.

Service-Learning Course Quality Measure 2: Faculty and Student Surveys. Based on scores derived from the student survey quality ratings described previously, each course cluster was assigned a quality rating of either low, medium, or high to correspond to a relative rating of course quality in the sample, with approximately one-third of each cluster occupying each category. 
Table 1

Service-Learning Course Syllabus Dimensions

\begin{tabular}{ll}
\hline Syllabus dimension (Heffernan, 2001) & Service-learning component \\
\hline Clearly describes how the service experience will be measured and what will be measured & $\begin{array}{l}\text { Linked to Learning Objectives } \\
\text { Defines the need(s) the service placement meets }\end{array}$ \\
$\begin{array}{l}\text { Presents course assignments that link the service placement and the course content } \\
\text { Specifies how students will be expected to demonstrate what they have learned in the place- } \\
\text { ment/project (journal, papers, presentation) }\end{array}$ & $\begin{array}{l}\text { Linked to Academic Content } \\
\text { Reflections }\end{array}$ \\
$\begin{array}{l}\text { Includes a description of the reflection process } \\
\text { Includes a description of the expectations for the public dissemination of students' work }\end{array}$ & $\begin{array}{l}\text { Reflections } \\
\text { Rescribes the nature of the service placement and/or project }\end{array}$ \\
$\begin{array}{l}\text { Specifies the roles and responsibilities of students in the placement and/or service project } \\
\text { (e.g., transportation, time requirements, community contacts, etc.) }\end{array}$ & $\begin{array}{l}\text { Service-Learning Preparation } \\
\text { Includes service as an expressed goal }\end{array}$ \\
\hline
\end{tabular}

\section{Results}

\section{Implementation of Service-Learning Courses}

Both faculty members and students responded to a series of questions regarding the implementation of their SL courses.

\section{Student Reasons for Taking a Service-Learning Course}

Students reported a variety of reasons for participating in the SL course (Figure 1). Of the students who reported on their reasons for joining $(n=1,018)$, the majority indicated that the SL course was required for their academic program (46\%). The least reported reason for taking the course was students' desire to make a difference in the community (18\%). Approximately $13 \%$ of students reported not knowing that they were enrolling in an SL course.

\section{Identifying Community Need}

In general, faculty members indicated that collaboration with community partners and past research or student discovery were the most common methods used to identify community need for SL projects.

\section{Importance of Service-Learning Course Projects}

Faculty members were asked to rate the importance of SL course projects on a number of dimensions. Results indicate that faculty members viewed "Engaging Students" as most important while "Personal Interest" and “Convenience / Availability” were rated as least important (see Figure 2). 
It was required as part of my academic program

The course sounded interesting

The course fit my schedule

I thought this would be good preparation for my career

I wanted to have a hands-on experience

Faculty or student recommended the course

I wanted to make a difference in my community

I didn't know this was a service-learning course when I registered

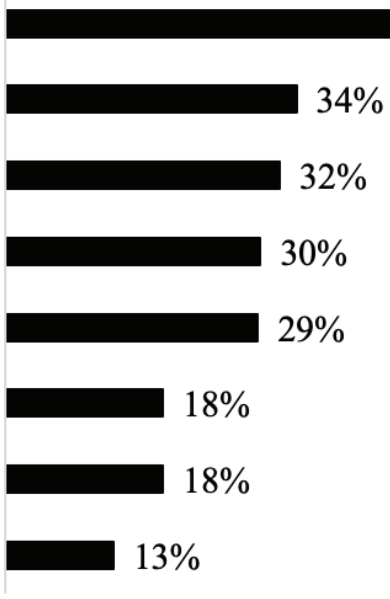

$\begin{array}{lllll}0 \% & 25 \% & 50 \% & 75 \% & 100 \%\end{array}$

Percentage of Respondents

Figure 1. Students' Self-Reported Reasons for Taking a Service-Learning Course

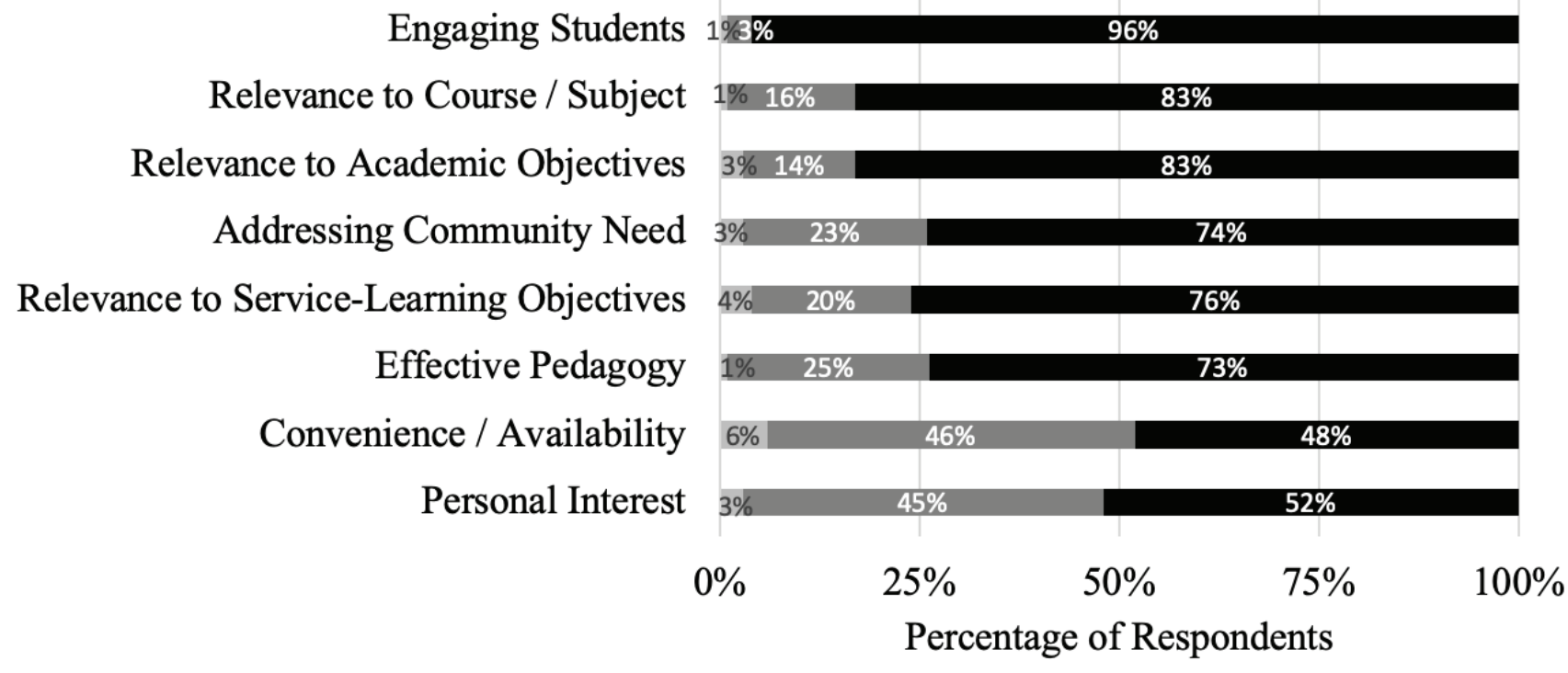

Not Important $\quad$ Somewhat Important $\quad$ - Very Important

Figure 2. Faculty Self-Reported Rating of Importance of Service-Learning Course Project

\section{Student Service-Learning Experiences}

Students were asked to identify the sites at which they completed their SL as well as provide short descriptions about their experiences. Student comments were coded by an SL expert and are presented in Table 2. Students most commonly reported working with schools and nonprofit sites in the fields of education or the environment. Interestingly, 105 students (20\%) provided descriptions that were not clearly identifiable as SL. For example, students" responses included descriptions such as "technology acquisition project" or "chem lab." 
Table 2

Student Service-Learning Sites and Descriptions

\begin{tabular}{lrr}
\hline SL experiences & $\boldsymbol{n}$ & \% \\
\hline \multicolumn{1}{c}{ Site } & \\
\hline Nonprofit & 192 & 37 \\
School & 153 & 29 \\
Business & 12 & 2 \\
Government agency & 11 & 2 \\
Error or missing & 157 & 30 \\
\hline & Type/description & \\
\hline Education, tutoring, mentoring & 164 & 31 \\
Environment & 67 & 13 \\
Computers, technology, data & 59 & 11 \\
Health and medicine & 35 & 7 \\
Homeless and housing & 24 & 5 \\
People and disabilities & 18 & 3 \\
Animals & 2 & $<1$ \\
Not clearly identified as SL & 105 & 20 \\
Error or missing & 51 & 10 \\
\hline
\end{tabular}

Note. $N=525$.

\section{Student Learning Outcomes}

Faculty members were also asked to indicate the kinds of student learning and developmental outcomes they expected the SL experience to enhance. Faculty members indicated that they expected "Engagement with Course Content" to occur most frequently and "Knowledge of Community Issues" to occur less often.

\section{Social Identities and Power Imbalances}

Faculty members were also asked two questions about students' opportunity to examine social identities and power imbalances they experienced through the SL course. The responses suggest that the courses were generally designed to address students' social identities and that the majority of courses created several opportunities for students to address power imbalances in their experiences: $71 \%$ of courses had at least some opportunities for students to explore their social identities in the community context, and $69 \%$ had at least some opportunities for students to understand power imbalances.

\section{Application of Knowledge, Skills, and Values}

Faculty members also responded to questions about students' abilities to apply the knowledge, skills, and values learned in the course to the community and clients' needs. Most faculty members indicated that students had at least some opportunities to apply and connect their knowledge to the community and clients' needs. Very few 


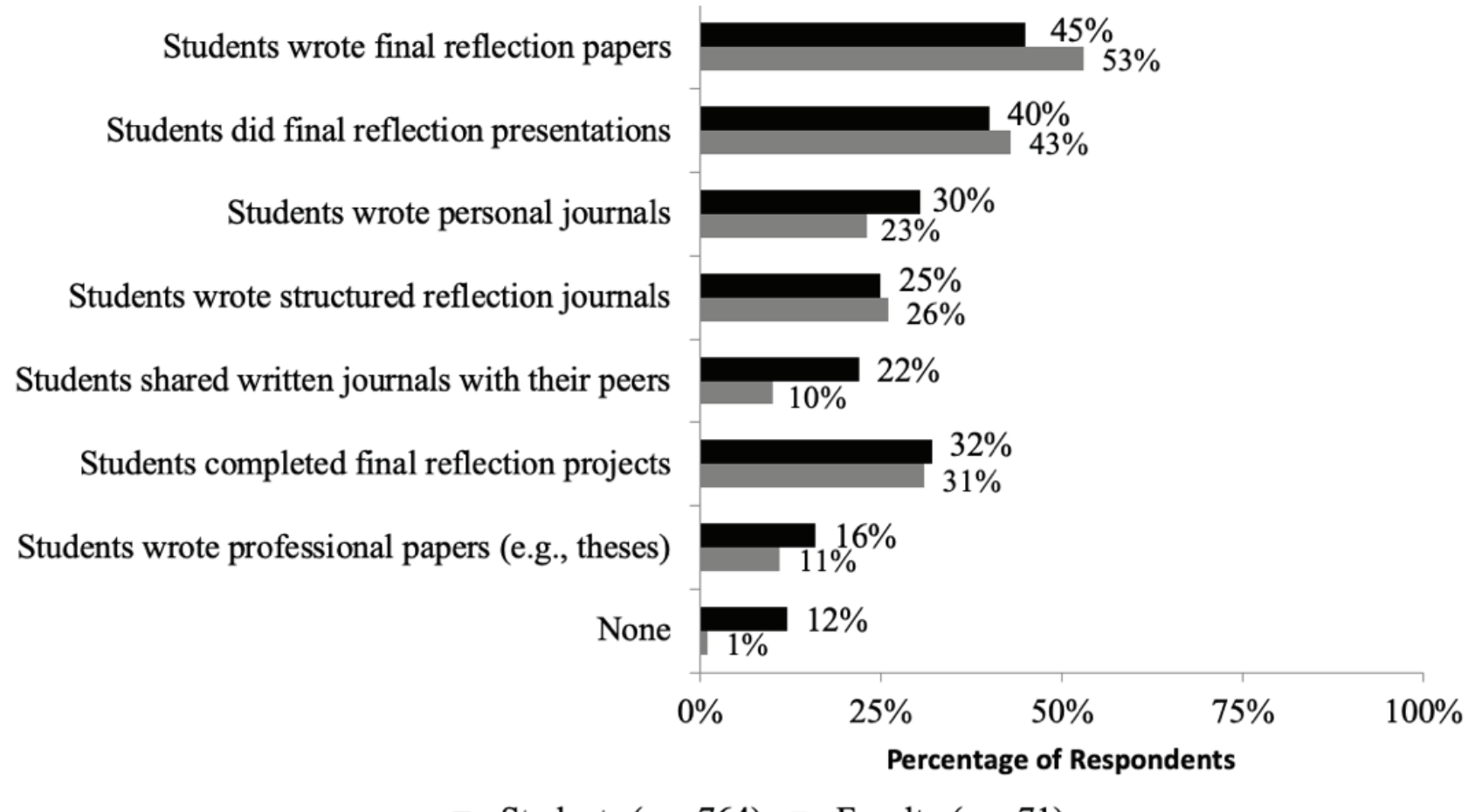

- Students $(n=764)$ - Faculty $(n=71)$

Figure 3. Reflection Strategies Reported by Faculty and Students

courses had no or minimal ways for students to apply knowledge to the community needs, and only $14 \%$ of courses had minimal opportunities for students to connect their knowledge to their community project.

\section{Faculty Changes in Pedagogy}

Faculty members rated changes in their pedagogy from the beginning to the end of the course using a 5-point scale $(1=$ Strongly Disagree to $5=$ Strongly Agree $)$. Faculty members indicated that they saw the biggest increase in their "Understanding of Community Needs and Issues" $(M=4.5, S D=.87)$, while the smallest increase was observed in their "Research Interests Broadening" $(M=4.18, S D=.92)$.

\section{Reflection Strategies}

Students and faculty members indicated how they implemented or participated in reflection strategies in their SL courses (Figure 3). Approximately half (53\%) of the faculty clusters reported having students write a final reflection paper, while $45 \%$ of students reported completing this reflection activity. One noteworthy finding is that students shared written journals with their peers about twice as often (22\%) than faculty estimated that they did (10\%). Although faculty and student reports of reflection strategies varied slightly, in general, faculty members and students provided consistent information about the course on surveys. 


\section{Essential Elements of Service-Learning}

Using the student ratings of the questions, the internal consistency reliabilities for components that consisted of two or more questions were assessed to determine the relationship between the items. Identifying these components, as well as the items that would theoretically be related to them, allowed us to perform a reliability analysis to assess the degree to which the survey items in each component did, in fact, go together. In other words, the reliability analysis tested whether the three community need items were similar to one another and thus measuring the same construct (i.e., Addressing Community Need).

The reliability analysis used Cronbach's alpha $(\alpha)$, the most commonly reported reliability statistic. Cronbach's alpha provides a value between 0 and 1, where higher values indicate that the items in the analysis are strongly related to one another and thus measuring a similar concept. Typically, a value of .70 or higher is considered acceptable, with values of .80 or higher most desirable.

The results of the reliability analysis were mostly positive, providing support for the raters' components. However, based on the results of the analysis, two of the components were split. We found that the six items related to Frequency of Communication represented two separate components. Similarly, the three items related to Academic Content represented two separate components.

We also found that the two items on the Service-Learning Preparation component did not go together, so one item was removed. When we took these findings into consideration, the research team identified eight different components of SL quality: six components composed of multiple rubric questions and two identified by single, stand-alone rubric items. A total of six SL components were developed as composite measures, including Reflections (5 items); Values Focus (5 items); Collaboration with Community (3 items); Addressing Community Need (3 items); Linked to Academic Content (2 items); and Communication with Community (3 items). These six components demonstrated acceptable, very good, or excellent reliability (DeVellis, 2017). Table 3 provides internal consistency ratings of composite variables. Two additional areas were also identified, but they represent only single items and no composite variables: Service-Learning Preparation and Linked to Learning Objectives. While the student scores were used to determine the reliabilities, the internal consistency remained when faculty ratings were combined with student ratings, meaning that student and faculty ratings were generally aligned. It should be noted that the analytical framework that we used was highly exploratory. Thus, the results reported should be considered descriptive in nature and used as a point of reference for future research activities regarding SL courses.

\section{Service-Learning Course Quality}

Two methods were used to assess SL course quality in the study. The first method relied on a coding of each course syllabus submitted by the participating faculty member at the beginning of the term. As shown in Figure 4 , only $35 \%$ of syllabuses $(n=27)$ were rated as high-quality syllabuses, meaning that they included most key dimensions of an SL syllabus. Roughly $40 \%(n=30)$, however, were rated as very low or low quality. Additional analyses indicated that $86 \%$ of the faculty members with high-quality syllabuses reported receiving a faculty 
Table 3

Exploratory Identified Service-Learning Components

\begin{tabular}{|c|c|c|}
\hline Service-learning component & Survey question & $\begin{array}{c}\text { Reliability } \\
\text { alpha }\end{array}$ \\
\hline Reflections & $\begin{array}{l}\text { The reflection activities were structured with clear directions and guidelines } \\
\text { Reflection activities were a regular part of this class } \\
\text { The reflection activities in this class allowed me to explore their personal } \\
\text { values } \\
\text { The reflection activities in this class allowed me to clarify my personal values } \\
\text { The reflection activities in this class allowed me to gain a better understanding } \\
\text { of the discipline theory and concepts }\end{array}$ & 0.94 \\
\hline Values Focus & $\begin{array}{l}\text { To what extent did you explore how your social identity is similar and differ- } \\
\text { ent from the community members you served? } \\
\text { To what extent did you acknowledge and analyze a power imbalance in the } \\
\text { service-learning experience? } \\
\text { To what extent did you connect your knowledge and values to those with } \\
\text { whom you serve? } \\
\text { How prepared did you feel to actively engage in civic participation through } \\
\text { the course? }\end{array}$ & 0.92 \\
\hline Collaboration with Community & $\begin{array}{l}\text { To what extent did collaboration take place between faculty and community } \\
\text { partner? } \\
\text { To what extent did collaboration take place between students and community } \\
\text { partner? } \\
\text { To what extent did collaboration take place between students and faculty? }\end{array}$ & 0.88 \\
\hline Addressing Community Need & $\begin{array}{l}\text { How did the course address community needs? } \\
\text { How was community need identified? } \\
\text { How much did you explore ways in which you might continue to apply your } \\
\text { knowledge and skills toward a community need or societal issue? }\end{array}$ & 0.83 \\
\hline Linked to Academic Content & $\begin{array}{l}\text { How was service learning integrated into the curriculum? } \\
\text { How did you apply academic skills or knowledge applied in real-world set- } \\
\text { tings? }\end{array}$ & 0.83 \\
\hline Communication with Community & $\begin{array}{l}\text { How many times a week were students at the service site? } \\
\text { Students were at the service site for a total of ___ hours? } \\
\text { In a typical week, how often did students communicate with the organization } \\
\text { or point of contact? }\end{array}$ & 0.74 \\
\hline Service-Learning Preparation & How were you prepared for your service-learning experience? & - \\
\hline Linked to Learning Objectives & To what extent was the course linked to learning objectives? & - \\
\hline
\end{tabular}

Note. All components were measured on a 1 to 4 scale, except for Reflections, which was measured on a 1 to 5 scale.

orientation or support from their on-campus SL center while $75 \%$ of faculty members with very low-quality syllabuses reported receiving that same support.

The second method to determine course quality relied on student ratings of quality based on survey responses. We analyzed the student scores of the identified SL components by cluster to explore student experiences by course. As shown in Figure 5, the average cluster score for each component was assigned a quality rating of low, medium, or high based on the average student rating. Initial analyses reveal that, in general, students rated the quality of Linked to Learning Objectives, Addressing Community Need, Collaboration with the Community, and Linked to Academic Content as high. The SL components with the lowest quality ratings were Communication with Community and Service-Learning Preparation. 
25

20

20

15

10

5

0
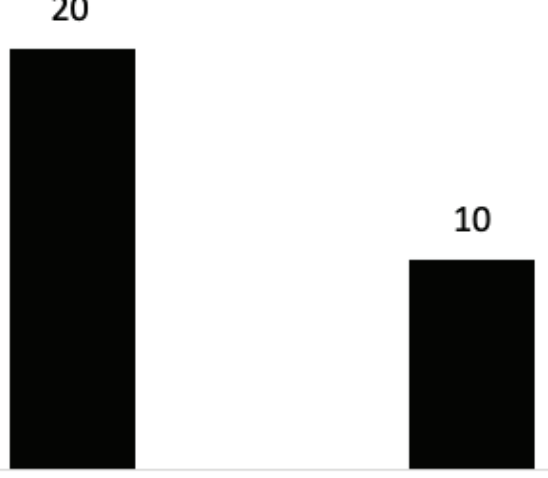

19

Very Low (Under 1)

Low (1-1.99)

Average Syllabus Rating

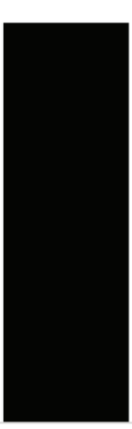

Medium (2-2.99)

High (3-4)

Figure 4. Quality of Service-Learning Course by Syllabus (in percentage)

Linked to Learning Objectives

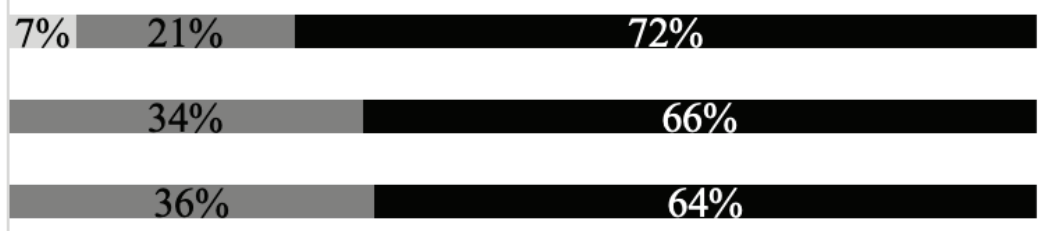

Collaboration with the Community

Linked to Academic Content 2\% $34 \%$ $64 \%$

Values Focus 2 $45 \%$ $53 \%$

Reflections

$2 \%$

$51 \%$

$49 \%$

Service-Learning Preparation

Communication with Community

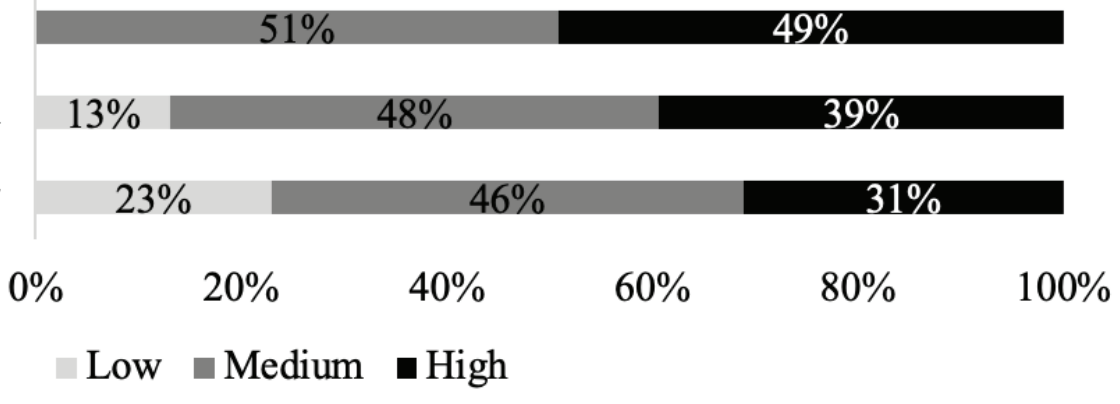

Figure 5. Service-Learning Components Present in Courses by Student Rating of Quality 


\section{Discussion}

This study highlights the need to examine actual implementation of SL courses on a wider scale, particularly those courses in STEM. We believe there are important findings from this study that could inform additional research.

First, faculty are highly concerned with the student experience within their courses. Our findings indicate that faculty members viewed "Engaging Students" as the most important aspect of their SL course projects and expected that students would frequently engage with the course content and be able to apply it in the real world.

Second, we believe that faculty members may benefit from teaching SL courses. For example, in this study, by the end of the term, faculty members reported an increased "Understanding of Community Needs and Issues." Additional research is needed to clarify how this process takes place; how faculty are using their increased understanding; and how their increased understanding shapes course content, structure, students' SL experience, and students' social agency.

Third, although faculty members have the best intentions to deliver a high-quality SL course experience, the way many SL courses are delivered does not currently meet this standard. For example, across the 3 years, the quality of faculty syllabuses typically fell into one of three main categories: high quality, medium quality, and very low quality. In some sense, these findings were unexpected, as those who teach SL courses and volunteered to participate in the study would likely be among those most prepared to integrate essential elements of SL pedagogy into their courses. Furthermore, we expected that those who were the most prepared to teach an SL course would have designed their course syllabus to more closely align with established guidelines for inclusion of language and content to guide students. We were also surprised to learn that faculty with high-quality syllabuses (86\%) and those with very low-quality syllabuses (75\%) both reported receiving a faculty orientation or support from their campus SL office. These results suggest that further qualitative study is needed to understand which components of support are currently being provided to faculty; the type, scale, depth, and frequency of professional development offered or attended; and how the degree and depth of support may result in both high-and low-quality syllabuses.

Fourth, these results indicate that students expect the SL experience to be highly aligned with the core content of a course rather than an ancillary aspect or just "making a difference." With respect to other SL course quality ratings, students rated the quality of their SL courses highly, with Linked to Learning Objectives as the highest rated component of the course. Students will often select courses that help them confirm or disconfirm career options while they are still in school. SL courses are a prime opportunity to expose students to meaningful engagement within a discipline and to support decision-making about possible career options.

\section{Limitations}

This study relied heavily upon student and faculty self-reported perceptions, which limits conclusions. For example, it is possible that more experienced faculty members might have had a different interpretation of SL 
definitions, which could have impacted their understanding of the survey questions. It is recommended that future research explore differences between faculty members with more SL experience and those with limited experience by incorporating additional qualitative research methods.

It should be noted that the analytical framework used was highly exploratory and meant to serve as a preliminary framework. Additional research is needed to validate the framework and operationalize and expand upon certain components (e.g., preparation, learning objectives, linked to academic content). Thus, the results reported should be considered descriptive in nature and used as a point of reference for future research activities regarding SL courses across different types of disciplines.

\section{A Practical Implication of This Study: A Case for Well- Prepared Faculty}

In the foreword of Reconceptualizing Faculty Development in Service-Learning/Community Engagement, Fink (2018) notes that while students are the obvious direct beneficiaries of service-learning and community engagement (SL/CE), faculty members also benefit:

They get to see their students learning the value of their discipline and/or a particular kind of knowledge, and, through reading the reflections, get to see how that learning is enriching students' lives - at the moment and potentially in the future.... this is not currently the norm in higher education. (p. $\mathrm{xx}$ )

Clearly, more professional development for faculty members teaching SL courses is needed to ensure that course content, and the syllabus used to describe course content, are more carefully aligned with best practices. For example, trainings should be designed to share the eight essential elements of SL that emerged from the literature, student ratings, and the initial analysis. Strategies and effective practices for integrating each element should be offered along with examples of activities and tools that can be adapted to the discipline and course content.

\section{Future Research Directions}

Additional evidence-based research on SL is needed to inform critical issues including the relationship between SL and student success, SL faculty development, and the types and effectiveness of SL partnerships.

Postsecondary institutions throughout the nation continue to face challenges in student retention and graduation rates. Additional evidence-based research to inform our understandings of student success measures and how SL can impact those measures will provide critical information to postsecondary institutions on how SL helps to retain a higher percentage of their student population. Furthermore, improving the information available about the relationship between SL and student success can inform state and national conversations to help postsecondary institutions better serve the increasingly diverse student population. 
As best practices in faculty development continue to emerge, it is imperative that the academy invest in properly prepared SL faculty as a strategy to meet student success goals. In their work on Models and Genres of Faculty Development, Gravett and Broscheid (2018) underscored the need for support units to cultivate relationships with faculty to effectively assist their learning in a multitude of interconnected areas that promote high-quality SL, including cultivating relationships with community partners, learning how to coach students through disorienting learning experiences, and assessing the effectiveness of SL experiences. The authors remind us that the most meaningful programs integrate teaching, scholarship, and service by deeply engaging the community partners' needs with the students' learning needs for mutual benefit.

Community partnerships are core to all SL experiences, and they vary widely. The CSU system as well as the SL field would benefit from a reflection and analysis on the types of partnerships and student learning outcomes that they produce in relation to the essential SL elements discovered here. Thompson and Jesiek (2017) provide a framework for transactional, cooperative, and communal partnerships in engineering that invites questions about the geographical context, duration, and interaction/engagement of community partnerships. Understanding how community partners and universities can integrate SL into the curriculum will improve experiences for students and the communities with which they partner.

\section{References}

American Institutes for Research. (2012). Broadening participation in STEM: A call to action. https://www.air. org/sites/default/files/downloads/report/Broadening_Participation_in_STEM_Feb_14_2013_0.pdf

Astin, A. W. (1999). Student involvement: A developmental theory for higher education. Journal of College Student Development, 40(5), 518-529. (Original work published 1984)

Astin, A. W., Vogelgesang, L. J., Ikeda, E. K., \& Yee, J. A. (2000). How service learning affects students. Higher Education, Paper 144.

Barrington, L., \& Duffy, J. (2007). Attracting underrepresented groups to engineering with service learning [Paper presentation]. American Society for Engineering Education Annual Meeting, Honolulu, HI, United States.

Billig, S. H. (2000). The effects of service learning. Service Learning, General, Paper 42.http://digitalcommons. unomaha.edu/slceslgen/42

Dary, T., Mangan, M., Betancourt, J., Hahn, S., Kamenov, M., Ready, P., \& Quinones, A. (2012). Engaging students through academic service-learning: National guide to implementing quality academic servicelearning. National Coalition for Academic Service-Learning. http://dropoutprevention.org/wp-content/ uploads/2016/09/Engaging-Students-Through-Academic-Service-Learning-Implementation-Guide.pdf

DeVellis, R. F. (2017). Scale development: Theory and applications (4th ed.). Sage.

Fink, L. D. (2018). Foreword. In B. Berkey, C. Meixner, P. M. Green, \& E. A. Eddins (Eds.), Reconceptualizing faculty development in service-learning/community engagement: Exploring intersections, frameworks, and models of practice. Stylus Publishing.

Garibay, J. C. (2015). STEM students' social agency and views on working for social change: Are STEM disci- 
plines developing socially and civically responsible students? Journal of Research in Science Teaching, 52(5), 610-632.

Graf, N., Fry, R., \& Funk, C. (2018, January 9). 7 facts about the STEM workforce. Pew Research Center. https:// www.pewresearch.org/fact-tank/2018/01/09/7-facts-about-the-stem-workforce

Gravett, E. O., \& Broscheid, A. (2018). Models and genres of faculty development. In B. Berkey, C. Meixner, P. M. Green, \& E. A. Eddins (Eds.), Reconceptualizing faculty development in service-learning/community engagement. Stylus Publishing.

Hatcher, J. A., Bringle, R. G., \& Muthiah, R. (2004, Fall). Designing effective reflection: What matters to servicelearning? Michigan Journal of Community Service Learning, 11, 38-46.

Heffernan, K. (2001). Fundamentals of service-learning course construction. Campus Compact.

Hurtado, S. H., Cabrera, N. L., Lin, M. H., Arellano, L., \& Espinosa L. L. (2008, May). The science of diversifying science: Underrepresented minority experiences in structured research programs [Paper presentation]. Association for Institutional Research Annual Meeting, Seattle, WA, United States.

Jacoby, B., \& Associates. (1996). Service-learning in higher education: Concepts and practices. Jossey-Bass.

Jameson, J. K., Clayton, P. H., \& Ash, S. L. (2013). In P. H. Clayton, R. G. Bringle, \& J. A. Hatcher,(Eds.), Research on service learning: Conceptual frameworks and assessment (Vol. 2A, pp. 85-110). Stylus Publishing.

Kuh, G. D. (2008). High-impact educational practices: What they are, who has access to them, and why they matter. American Association of Colleges \& Universities.

Lockeman, K. S., \& Pelco, L. E. (2013, Fall). The relationship between service-learning and Conceptualizing, assessing, and investigating academic learning in service learning degree completion. Michigan Journal of Community Service Learning, 20, 18-30.

Matthews, P. H., Dorfman, J. H., \& Wu, X. (2015, Fall). The impacts of undergraduate service learning on postgraduation employment outcomes. International Journal of Research on Service-Learning and Community Engagement, 3(1). https://journals.sfu.ca/iarslce/index.php/journal/article/view/109

Milgrom-Elcott, T. (2019, January 8). These 5 trends will dominate STEM + education in 2019. Forbes Magazine. https://www.forbes.com/sites/taliamilgromelcott/2019/01/08/these-5-trends-will-dominate-stem-education-in-2019/\#50ff5e31adfc

National Academy of Engineering. (2010). Engineering, social justice, and sustainable community development: Summary of a workshop. The National Academies Press. https://doi.org/10.17226/1288

National Service-Learning Cooperative. (1999). Essential elements of service-learning. National Youth Leadership Council. https://www.nylc.org/page/standards

Pascarella, E. T., \& Terenzini, P. T. (2005). How college affects students: A third decade of research. Jossey-Bass.

Peace Corps. (1998). Looking at ourselves and others. https://files.peacecorps.gov/wws/pdf/LookingatOurselvesandOthers.pdf

President's Council of Advisors on Science and Technology, Executive Office of the President. (2012, February). Report to the President: Engage to excel: Producing one million additional college graduates with degrees in science, technology, engineering, and mathematics. https://obamawhitehouse.archives.gov/sites/default/files/ microsites/ostp/pcast-engage-to-excel-final_2-25-12.pdf 
Roy, J. (2019). Engineering by the numbers. American Society for Engineering Education. https://www.asee. org/documents/papers-and-publications/publications/college-profiles/2018-Engineering-by-Numbers-Engineering-Statistics-UPDATED-15-July-2019.pdf

Thompson, J. D., \& Jesiek, B. K. (2017, Spring). Transactional, cooperative, and communal: Relating the structure of engineering engagement programs with the nature of partnerships. Michigan Journal of Community Service Learning, 23, 83-99.

Western Region Campus Compact Consortium. (2009). Faculty engagement in service-learning and communitybased research: WRCCC survey data summary. https://www.weber.edu/wsuimages/CommunityInvolvement/Faculty/WRCCC\%20Faculty\%20Survey\%20Full\%20report.pdf

\section{Authors}

CATHY AVILA-LINN provides coaching and professional development for creative leaders. She specializes in social justice education, organizational development, and leadership coaching, and she provides effective, participant-friendly learning environments, processes, and tools.

JUDY BOTELHO is Director of the Center for Community Engagement in the California State University, Office of the Chancellor. Judy delivers, inspires, and sustains high-quality learning opportunities by promoting programs and initiatives that create inclusive spaces for authentic relationships to occur and that honor personal growth, self-empowerment, and life-long learning.

REBECCA EDDY is the founder and current President at Cobblestone Applied Research \& Evaluation, Inc. In addition to her work as an evaluator and applied researcher, she has taught evaluation students and professionals for the past 20 years. She received her PhD in Applied Cognitive Psychology and has spent her career applying the principles of learning and cognition to the evaluation of educational programs, primarily for underserved students.

NICOLE GALPORT is a research associate at Cobblestone Applied Research \& Evaluation, Inc. and a doctoral candidate at Claremont Graduate University, where she is pursuing her degree in psychology with a concentration in evaluation and applied research methods. As an evaluator, she has worked on a range of projects throughout the education spectrum including the evaluation of STEM education programs and retention/graduation initiatives. As a doctoral student, Nicole's research focuses on evaluator competency development, professional development, and training programs. 